\title{
Self-estimation of Intercultural Competencies: Advantages of 21st Century Trainings!
}

\author{
Nina Dziatzko ${ }^{1}$, Christopher Stehr ${ }^{2}$, Franziska Struve ${ }^{2}$ \\ ${ }^{1}$ Diversia Consulting \\ ${ }^{2}$ German Graduate School
}

\begin{abstract}
The ongoing globalization of businesses, cultures and interactions makes the increasing need for managers with global skills and intercultural competencies obvious. Whereby the demand for welleducated young people is rising, international business schools and providers of intercultural trainings are confronted with the need to satisfy the expectations of the business. At no point in history the opportunities for young academics have been so broad as they are today. At the same time the requirements to meet job descriptions are getting more and more unspecific and in some cases, they seem to be unreachable. The applicants are wondering, if they have the right abilities to succeed. But do companies know what skills their employees really need? Do they for example name intercultural competencies in job advertisements in an international or global context? The answer is: most of the time they don't. But what can students do proactively before applying for a job operating in an international context? And what can the company do if they have highly skilled people with a lack of intercultural competence? Most of the time the answer is: Just do an Intercultural Training. But therefore the Intercultural Training has to be effective. This research aims to evaluate different types of Intercultural Trainings to find the most effective way of teaching and training intercultural competencies - from a practical perspective.
\end{abstract}

\section{Introduction}

What are the abilities a global leader needs to leverage in order to use the opportunities of globalization? Our globalized world has an obvious need for managers with cultural intelligence, globalization skills as well as global leadership skills [1] [2] [3]. During the last decades, the interconnectedness of cultures and economies increased, and global economies grew together [4]. Irving mentions: "If you want to succeed on today's volatile global economy, you must be prepared to do business all around the world." [5] This means nearly everyone has to interact between different cultures and make decisions on a global scale

[6]. Therefore, intercultural competencies and intercultural trainings are not only desirable anymore, but necessary to be successful in the business of the future [7]. While most practitioners agree that preparing students and employees for the requirements of a global business environment is important, the question of how this education is carried out best, is often left unclear [4]. Critical factors for today's success are leaders who can manage the organization effectively through global challenges, such as: complexity, ever changing environments, as well as ambiguity [8]. The global shortage of people who possess this talent has created a necessity to find or to develop effective global leaders. An important issue is the combination of leadership and management skills. For Prewitt et al. one of the major differences between leadership and management "is the ability to influence change", because managers are used to show a stable direction whereby leaders create directions according to an ever-changing environment [3]. Beechler and Baltzley [9] on the other hand, argue that the global mindset is the necessary "way of thinking" that enhances the leader to compete in the global environment by giving him a broader perspective on a global as well as on a local level. Only few researchers combine the concepts of global mindset with global leadership although it has been shown that a global mindset supports the development of global leadership [8]. In other words: the concept of the global mindset covers holistic competencies which are commonly associated with those needed for global leadership [10]. Several methods like online, virtual multicultural team projects [11] or global virtual teams from several universities in their international management courses [12] where evaluated to teach the students these globalization skills, enhance their cultural intelligence and develop global leadership skills. "For students to function effectively in a global work environment they must develop the cognitive abilities, attitudes, and behavioral skills that are essential for success in a global workforce. Core to this mission is the formation of a "global mindset" [13]". The following research carried out at German universities, business schools and companies focus on another way to train intercultural competencies to students. Business schools tend to focus more on practical implications whereas universities emphasize theoretical knowledge. The lack of explicitly addressing business related activities during university studies (e.g. cultural understanding as a part of globalization skills) can lead to 
uncertainty of the students regarding the value of these competencies after the course [14]. Therefore, intercultural trainings might be less effective if they are not interactive (see definitions in the next part). This paper aims to give trainers hands-on material, helping them develop the ability to teach a (previously defined) set of intercultural competencies to their participants. This way the main questions are: Which effect has the conception and the success of an intercultural training on the perception of learning within the group? Which effect do different intercultural trainings/ lectures have on the selfestimation of the participants' competencies? How does the explicit consideration of group dynamics positively influence intercultural trainings? Our approach aims to show the effect of interactive trainings on competencies related to self-reflection and self-awareness - what Holt and Seki call "being" [15] - and how they influence the students' selfestimation.

\section{Theoretical framework}

In the following article we differentiate between training and lecture. According to the authors, training is highly interactive whereas lectures are less:

Conventional lecture: $0-20 \%$ interaction (knowledge is provided to $80100 \%$ by the trainer/professor)

Conventional training: $21-60 \%$ interaction (knowledge is provided to $4079 \%$ by the trainer/professor)

21st century training [20]: $61-80 \%$ interaction (knowledge is provided to $2039 \%$ by the trainer)

Different methods to train intercultural competencies to students are mentioned in other research, such as training on Cultural intelligence (CI) or CrossCultural Management (CCM) courses [16]. Ramsey/ Lorenz examined that is it possible to teach CQ as part of intercultural competencies in a classroom and that the rise of this competence after the course was positively linked with the commitment and satisfaction of the students. Only a limited amount of studies examine the effect of intercultural trainings on participant's intercultural competencies [17]. Empirical studies highlighted benefits of intercultural trainings, such as: a better adjustment and performance of expatriates [18], increase in intercultural essentialism (one's belief's that culture influences the way individuals act, feel, and behave) [19], a positive development of cultural intelligence and competencies [20]. Dating back to the review of training methods by Brislin and Yoshida 1994 there are five approaches to conduct intercultural trainings: cognitive, attributional, experiential, sustaining self-awareness and behavioral [21][[22].

\subsection{Intercultural competence and related concepts}

The following discussion includes (beside others) terms like "cosmopolitanism" [23] [24], "cultural intelligence" [16][25] [26] and "global mindset" [27][28] as well various definitions and measurement approaches. As Intercultural competence and Global mindset are both derived from a cross-discipline background including research from international business strategy, organizational behavior, as well as from cognitive and cross-cultural psychology [29] [30], it is necessary for this research to provide own definitions which can easily be understood by the participants during the answering process (see research design). A main difference between global mindset and intercultural competence is the following: Global mindset is focused on leadership whereas intercultural competence might be applied on everybody, those who have leadership responsibility and those who don't. For this research intercultural competence is defined as "one's knowledge and ability to successful deal with intercultural encounters" [31].

\subsection{Learning Theory}

Early 2004 [21] supports that intercultural trainings for global managers should include metacognitive, motivational and behavioral components.

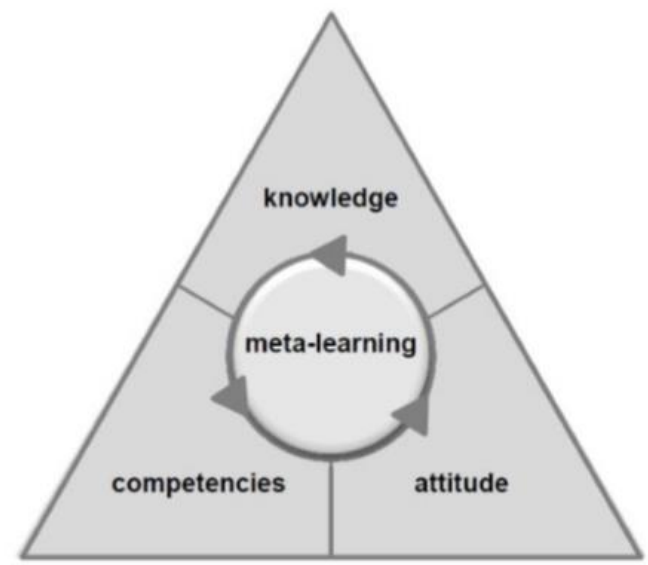

Figure 1. Learning outcomes, source: own figure, based on [32]

Figure 1 shows different fields training methods can influence. They can focus on providing knowledge like giving background on a country's history and political system, for example. The competencies can be those mentioned in the study or can also comprise 
language skills. The attitude might be questioned or reinforced through another method, or part of a method.

It is important to know that a method can impact several fields of action at the same time, by providing knowledge and influencing one's attitude. This means the fields are not separated. In order to take away the experience from the used method it is important to focus on meta-learning, meaning talking about the learning itself and the target of the used method. The arrows in figure one show that every phase of meta-learning is a cycle which puts the knowledge in the right frame (for more background on the framework of 21 st learning skills refer to [33]).

\subsection{Structure and flexibility of trainings}

Comparing conventional and what the authors call 21st century trainings, the following observations can be made: although there are some similarities regarding the structure, the content, and especially the interactivity level, differ widely. Regarding the structure referring to the situational flexibility of content and applied methods, such as to start with asking for expectations and already existing experiences in the intercultural context are similar. This part was longer at the trainings of Provider $\mathrm{P}$ and therefore it can be assumed to be more intensive. Further, both groups of trainers mentioned similar learning objective.

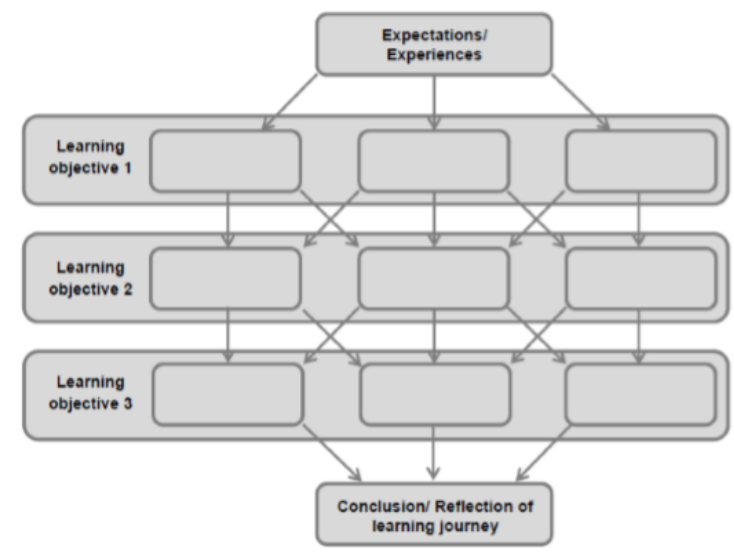

Figure 2. Similarities in overall structure, own figure

Further both types of intercultural trainings ended with a conclusion of the learned contents. This part was longer (more time consuming) at the training of Provider P. Therefor it is assumed that this part which they call "learning journey recapitulation" was more intense (see Figure 2). From a literature perspective informational and experiential training are working best in tandem, whereas the majority of existing intercultural training approaches is a mix of all existing methods based on the hope that at least something will work [21]. Taking a deeper look at the different structures of the evaluated trainings it is necessary to divide them into different types of methods, tools, which we sum up using the term sequence as a part of the training. This sequence is limited in terms of time and in accordance with a defined learning objective. Further, the sequences are characterized by their level of interactivity.

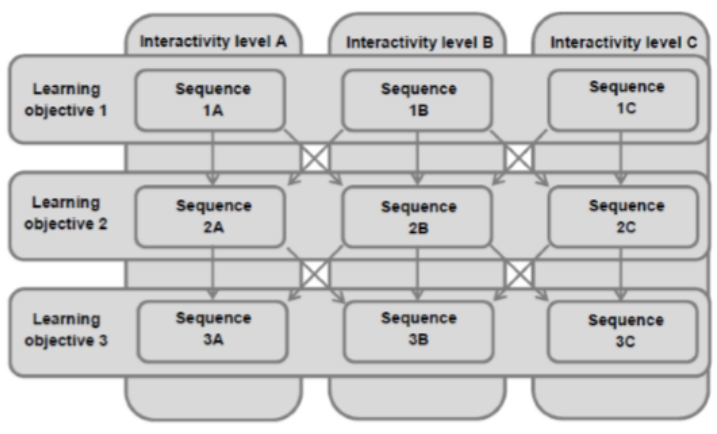

Figure 3. Structure of training by Provider P, own figure

Interactivity level A refers to experiential training with its emphasis on applied training including roleplays and simulations. This kind of training sequences are probably only offered by provider $\mathrm{P}$ as it is typically more emotionally demanding for participants and trainers [21] and therefore might require coaching skills from the involved trainers.

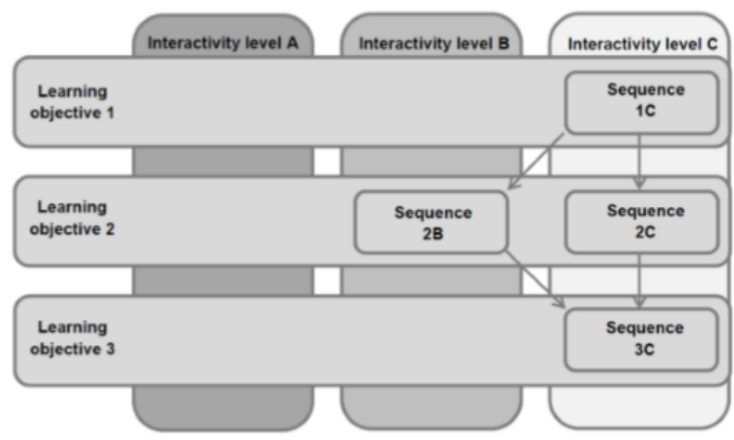

Figure 4. Structure of training by Provider I, own figure

Interactivity level $\mathbf{B}$ refers to small interactions of applying learned theory, such as games where the participants have to adjust to changing rules. Sequences like these are used to show the participants how they might mediate between individuals of different cultures. They should be the initial step of reflecting about the learned theory. Interactivity level $\mathbf{C}$ mostly similar to the conventional lecture described earlier, as it is mostly based on knowledge provided by the trainer and enriched by discussions and examples. 
Comparing both trainings (by observation and discussion with the trainers) it became obvious that the trainings of Provider P changed flexibly between different intensities of interaction, in accordance with the target group's needs. The trainings of provider I stayed mainly in the lower interactivity levels, focusing on knowledge sharing, instead of knowledge transfer.

The critique on current approaches of intercultural trainings include [21]: 1 . To neglect the unique requirements of each participant referring to the intercultural interaction in terms of intensity, duration and type of interaction. 2. The focus on cognitive and knowledge-based trainings including specifics of certain countries. 3 . To assume a strong interlinkage between cultural values and norms and the individual's behavior. 4. Focusing on analogical learning, assuming that the participant is able to find intellectual connections between the tools applied and future situations. Challenges implied by these approaches: 1 . Only few of the content learned might fit to the personal uncertainties referring future intercultural situations. This might lead to less motivation to participate and less satisfaction with the training. 2. This might lead to stereotyping. Furthermore, it does not take into consideration specific situations and the creation of trust needed for example when working in multicultural teams. Therefore, the required knowledge these people need to feel safe interacting cannot be trained (fast enough). It would be better to be equipped with the metacognitive skills to acquire only the necessary information to cope with this particular situation [21]. 3. This approach seems to be too simplistic, as there are studies such as Meyer 2014 [33] which sets the individual behaviors in relation to the norms of the individuals' cultural background. Therefor every individual can have different cultural traits which can be independently from their cultural origin or background. 4. Most research says that there is a limited capacity of transferring the learned concept to a real situation [21]. When using metacognitive teaching tools however, the transfer can be made more easily [34].

\section{Methodology}

Concepts like e.g. intercultural competence were evaluated with several methods. Self-assessment of the students, with about $85 \%$ of agreement as the best way to assess the intercultural competence of students [35], seems thus the appropriate method for evaluating the teaching of globalization skills. Therefore, self-assessment at the end of courses is used to measure the estimation of the comprehension, the specific competencies, the performance or the increase of those goals [36]. Following the practical implications of Sitzmann et al. the students get periodic feedback on their performance during the course to minimize the probability of affective rather than cognitive answers. This paper outlines lessons learned based on the evaluation of four different intercultural trainings for management students as a first step of a possible research on evaluating intercultural trainings. Additionally, two reference groups, which only had conventional lectures on "global business challenges", were taken as reference groups.

\subsection{Research design}

From end of December 2015 until September 2017 six groups of students were evaluated (see Table 1) including two MBA classes were evaluated with a quantitative survey. The main differences between the observed intercultural trainings are the amount of theoretical input in relation to hands-on experiences, the number of trainers as well as the used methods to teach implicit cultural rules. Both groups contain management students with the willingness and perspective to work abroad or to work in an international context. The research is carried out with a pre-training-survey and a posttraining-survey which consists of a selfestimation of up to 19 identified intercultural competencies including global mind-set skills. The surveys focus on up to 19 central abilities to name them: adaptability, scope of understanding/ knowledge of cultures, ability to communicate, language skills, ability to work in teams, differentiation, integration, expert intuition, ability to analyze, flexibility, selfawareness, curiosity, tolerance for ambiguity, ability to solve problems, ability to build trust/ be empathic, cosmopolitanism, openness, empathy and resilience (see. Appendix 2 for derivation of the competencies). The students were asked to estimate their own abilities immediately before and after the trainings and lectures. Each of the competencies was assigned a number on a scale ranging from 1 (lowly pronounced ability) to 10 (highly pronounced ability). All participating students got definitions of the competencies to ensure a similar understanding of each ability during the research (see. Appendix 3).

\subsection{Understanding of key competencies}

The evaluation of certain competencies makes it necessary to define those, making sure that there are no misunderstandings which might lead to errors in the evaluation. The key competencies the authors will focus on are: differentiation, expert intuition, ability to analyze, flexibility, self-awareness, tolerance for ambiguity and resilience. Differentiation as one aspect of cognitive complexity construct (beside integration) is the ability to hold and apply several valid but competing and complementary interpretations of a domain or situation [9]. Expert intuition is understood as 
"Integration of your experience over time [...] applied to a particular challenge" [9]. Ability to analyze is to assess quickly whether a situation is typical or atypical [9]. Flexibility is defined as the "ability to be adapt easily" [37]. Self-awareness "to understand [..] own strengths and weaknesses, [...] emotions and [...] impact on others" [9]. Tolerance for ambiguity is defined as the "individual differences in reactions to the complex, unfamiliar, confusing, indeterminate, and incomplete stimuli that fall within the conceptual domain of ambiguity" [38]. Or as the "ability to endure ambiguities, inconsistencies, uncertain and unstructured situations or different expectations and roles that are addressed to one's own person" [39]. Further it "predicts short and long-term reactions to a spectrum of situational characteristics relevant in a wide variety of life contexts and outcomes [40]. Resilience was defined as the "Capacity to recover quickly from difficulties and changes" from scientific perspective this definition has to be more precise. Therefor the definition from Sakar [41] is used to examine the results. "The role of mental processes and behavior in promoting personal assets and protecting an individual from the potential negative effect of stressors" [41] (for further discussion of this context see [42]). This definition focuses on psychological resilience, the process-like definition includes the perspective that resilience is a capacity which develops over time, least it focuses on maintaining the normal functional level rather than restoring or enhancing a certain function.

\section{Findings}

This research consists of various findings, whereas this article focuses on the influence of the structure of an intercultural training as well as the influence of the approach of different providers on the outcome of the trainings as perceived by the participants.

\subsection{Sample}

Until now in total 83 students participated in this research. $31 \%$ of them were female and $69 \%$ of them were male, whereby the average age was 30,8 years. The sample is divided into six groups, based on the provider of the intercultural trainings and the already existing training groups. Therefore, provider I belongs to group $\mathrm{L}$ and to group $\mathrm{M}$, whereas provider $\mathrm{P}$ belongs to group $\mathrm{H}$ and group $\mathrm{A}$. The groups M14 and M16 were taken as reference groups. The aim of including reference groups was to show developments in the self-estimation of students based on interactions (in this case a lecture on global business challenges) to contrast these effects to the influences of intercultural trainings.

\subsection{Evaluation of data}

Within the period of December 2015 until September 2017 the 83 students were asked to fill in a pretraining-survey and an after-training-survey. Therefore 166 surveys were collected with a response rate of $100 \%$. For each student an average self-estimation before the trainings as well as after the trainings was calculated using the 19 estimations in each survey. The difference between those values was calculated and used to get an average change in self-estimation per group. Further, the average selfestimation of each group before and after the training was calculated. Considering the change in average self-estimation of the groups, each group had on average an increase in the self-estimation of their own skills, abilities and competencies. The overall increase was between 0.05 and 1.11 on a 10-pointscale (see. Appendix 4). Further, the variety of selfestimations within the groups (highest average selfestimation and lowest average self-estimation) was recorded. The lowest value in each group before the training/ lecture varied between 5.63 and 6.75 whereby the highest self-estimation before the trainings differed between the groups from 8.0 to 8.92. After the trainings the lowest self-estimation was between 4.42 and 7.37, whereas the highest selfestimation after the trainings was between 8.32 and 9.63 (see. Appendix 4). It is interesting to consider that the variety of the estimations within the groups of provider I increased in both cases whereas the variety of estimations within the groups decreased for the groups of provider P. Within the reference group both changes occurred. The group A from provider $\mathrm{P}$ had the highest increase in terms of average self-estimation of a group with an average increase in self estimation of 1.11. This way this research provides a guideline for both academic institutions as well as companies for the decision between different types of intercultural trainings, in accordance with the skills that are to be trained. Therefore, the education of future global managers can get optimized.

\section{Overall effects of intercultural trainings}

As the groups have different changes in their selfestimation on average, which differ between the groups from 0.05 to 1.11 on average per group, it is necessary not only to look at the total changes but also on the average changes. Therefore, the average change per competence per group is calculated (between 0.05 and 1.11) and the changes per competency which are above the individual average change level of the group are highlighted (see. Appendix 5 and 6). If we take a look on the highlighted changes, it is obvious that "understanding and knowledge" as well as 
"integration" increased above average level for all intercultural training groups (see. Appendix 6).

\section{Influence of Provider I}

Comparing the overall average changes in competencies, there are some competencies which have been developed over average by the students in the trainings from the same provider. Group L and group $\mathrm{M}$, both from provider I both had overall average changes in the following competencies: differentia on, expert intuition, ability to analyze and flexibility.

\section{Influence of Provider $P$}

Comparing the over average changes in competencies for the group $\mathrm{H}$ and $\mathrm{A}$ from provider $\mathrm{P}$, the competencies self-awareness, tolerance for ambiguity and resilience got developed over average in both groups.

\section{Characteristics of the reference groups}

Comparing the over average changes of the reference groups it shows that, similar to the trainings of provider $\mathrm{P}$, the competencies selfawareness and tolerance for ambiguity were further developed. Besides, the competencies expert intuition and differentiation were developed over average. The similarities referring to self-awareness and tolerance for ambiguity might occur, because the trainer/ lecturer of the reference groups was partly involved in the intercultural trainings of provider $\mathrm{P}$.

\section{Implications}

Overall, an interesting result was the difference in estimations of the groups related to the provider. Especially, the overall effects in terms of selfestimation of understanding/ knowledge of cultures as well as integration showed possible similarities between the contents not only of the intercultural trainings, but also of the trainings with the lecture, which was taken as reference group. Looking at the results we tend to see a positive evolution of the competencies between before the training and after the training. For the competencies which seem to have deteriorated, the team of trainers noticed a certain modesty of the students in evaluating their skills while being confronted to actual situations, or even having experienced small culture-shocks during the training. The different exercises showed how hard it can be to put competencies into practice when being in a stressful situation. All in all, the varying self-estimations of the peer groups show the effect different types of adult education have in comparison.

\section{Further Research}

The weaknesses of this research are for sure the still small sample which can always be extended in further research. There could be a bias due to the self-estimation of the students as only method, even though the authors are aware of the bias selfassessment tools can bring along. Additional reference groups, control groups and methods such as estimation by the examiner or supervisor could improve the validity of this first study. Furthermore, the 19 categories might change over time and thus be covered by further literature review. Further research could focus on those competencies which have not

changed considerably through the trainings and shed light on the reasons for this phenomenon. Last the self-estimation has to be appropriately taken into account, as a lecture is not a common situation and neither had the students' time to reflect the learned competencies in depth, nor did they get the possibility to prove their (new) competencies in practice. Most researchers agree on the fact that expatriation is the best way to learn intercultural skills [43] so the question might arise how intercultural trainings can be conducted as if they were "miniexpatriations". Depending on the type of global manager you want to get [44], you might need a different type of training.

\section{Conclusion}

The following research showed how important it is to choose the right provider for the right need or the right target group. Then, according to the available time and the needs, it makes sense to choose between different types of training: more interactive or less. This approach is directly linked to the conception of the training: the planning of a program in accordance with a target group's needs before and during the training. Thus, the success of the training is not directly linked to a positive feeling during the training. As mentioned before, the best trainings are those provoking a small culture-shock. The trainer's task is then to ensure that this shock is digested by the end of the training. This is why the authors recommend intercultural trainers to be coaches as well, in order to ensure the group's selfreflection during the training. Only then we can speak of a successful training. Our research showed the different effects different intercultural trainings can have on the self-estimation of the participants on their competencies even though the training should foremost take into consideration the specific needs and learning goal of the participants. If the team of trainers is able to take into consideration the participants' needs and adapt the training concept in real-time, it is likely to have a high impact on the individuals as well as on the group. This is why the authors hold the opinion that a team of trainers can 
respond more effectively to those changes than an individual trainer could do it. This approach combined with self-reflection and meta-learning, as well as highly interactive elements are the ingredients for a 21 st century training.

\section{Acknowledgements}

The publishing of this article would not have been possible without the input from our students and training participants. We would especially like to thank Jörn Gremm who continued developing the global skill set for his master thesis.

\section{References}

[1] Caganova, D. / Cambal, M. / Weidlichova Luptakova, S. 2010, Intercultural Management Trend of Contemporary Globalized World, p. 51-54.

[2] Dusoye, I. 2013, Global mind-set and Global Leadership competencies as shapers of Organisational Learning; Evidence from Globalizers ‘ narrations.

[3] Prewitt, J./ Weil, R./ McClure, A. 2011, Developing Leadership in Global and Multi-cultural Organizations, International Journal of Business and Social Science, Vol. 2, No. 13, p. 13-20.

[4] Irving, J. A. 2010, Educating global leaders: Exploring intercultural competencies in leader-ship education. Journal of International Business and Cultural Studies, 3:1-14

[5] James G. Clawson 2014, University of Virgina, Darden School of Business.

[6] Bücker, J., Poutsma, E. 2010, Global management competencies: a theoretical foundation. Journal of Managerial Psychology. 25 (8): 829-844.

[7] Eisenberg, J., Lee, H.-J., Brück, F., Brenner, B., Claes, M.-T., Mironski, J., Bell, R. 2013. Can Business schools make students culturally competent? Effects of cross-cultural management courses on cultural intelligence. Academy of Management Learning \& Education. 12 (4): 603621.

[8] Caligiuri, P. \& Tarique, I. 2009, Predicting effectiveness in global leadership activities. Journal of World Business, 44, p. 336-346.

[9] Beechler, S./ Baltzley, D. 2008, Creating a Global Mindset, in: Chief Learning Officer, p. 40-45.
[10] Cohen, S. L. 2010, „Effective global leadership requires a global mindest", Industrial and Commercial Training, Vol. 42, No. 1, p. 3-10.

[11] Erez, M./ Lisak, A./ Harush, R./ Glikson, E./ Nouri, R./ Shokef, E. 2013, Going Global: Developing Management Students' Cultural Intelligence and Global Identity in Culturally Diverse Virtual Teams, Published online before print May 31, 2013, doi: 10.5465/amle.2012.0200, ACAD MANAG LEARN EDU September 1, 2013 vol. 12 no. 3 p. $330-355$.

[12] Taras, V./ Caprar, D. V./ Rottig, D./ Sarala, R.M./ Zakaria, N./Zhao, F./ Jiménez, A./ Wankel, C./ Si Lei, W./ Minor, M.S./ Bryła, P./ Ordeñana, X/ Bode, A./ Schuster, A./ Vaiginiene, E./ Froese, F. J. /Bathula, H. / Yajnik, N. / Baldegger, R. /Huang, V. Z. 2013, A Global Classroom? Evaluating the Effectiveness of Global Virtual Collaboration as a Teaching Tool in Management Education, Published online before print June 14, 2013, doi: 10.5465/amle.2012.0195, ACAD MANAG LEARN EDU September 1, 2013 vol. 12 no. 3 p. 414-435.

[13] Lovelace, K. J./ Parent, J. D./ Litvin, D. R. 2015, The Global Organizational Behavior (OB) Project: Using Comparison Learning to Enhance Students' Global Mindset in: Journal of the Academy of Business Education16 (Spring 2015): p. 73-96.

[14] Blasco, M. 2009, Cultural Pragmatists? Student Perspectives on Learning Culture at a Business School doi: 10.5465/AMLE.2009.41788841 ACAD MANAG LEARN EDU June 1, 2009 vol. 8 no. 2 p. 174-187.

[15] Holt, K./Seki, K. 2012, Global Leadership: A Developmental Shift for Everyone, in: Industrial and Organizational Psychology, No. 5, p. 196-215.

[16] JASE R. RAMSEY/ MELANIE P. LORENZ Exploring the Impact of Cross-Cultural Management Education on Cultural Intelligence, Student Satisfaction, and Commitment Academy of Management Learning \& Education, 2016, Vol. 15, No. 1, 79-99. http://dx.doi.org/10.5465/amle.

2014.0124

[17] Eisenberg, J., Lee, H.-J., Brück, F., Brenner, B., Claes, M.-T., Mironski, J., \& Bell, R. 2013. Can Business schools make students culturally competent? Effects of cross-cultural management courses on cultural intelligence. Academy of Management Learning \& Education. 12(4): 603-621.

[18] Morris, M. A., \& Robie, C. 2001. A metaanalysis of the effects of cross-cultural training on expatriate performance and adjustment. 
International Journal of Training and Development. 5: 112-125.

[19] Fischer, R. 2011. Intercultural training effects on cultural essentialism beliefs and cultural intelligence. International Journal of Intercultural Relations. 35: 767-775.

[20] Rosenblatt, V., Worthley, R., \& MacNab, B. 2013. From contact to development in experiential cultural intelligence education: the mediating influence of expectancy disconfirmation. Academy Management of Learning and Education. 12: 356379.

[21] Earley, P. 2004 The Elusive Cultural Chameleon: Cultural Intelligence as a New Approach to Intercultural Training for the Global Manager, Academy of Management Learning and Education, Vol. 3, No. 1, 100-115.

[22] Brislin, R.W. \& Yoshida, T. 1994. Intercultural communication training: An introduction. Thousands Oaks, CA: Sage.

[23] Harvey, D. (2000), "Cosmopolitanism and the banality of geographical evils", Public Culture, Vol. 12 No. 2, pp. 529-64.

[24] Vertovec, S. and Cohen, R. (2002), Conceiving Cosmopolitism: Theory, Context and Practice, Oxford University Press, Oxford.

[25] Earley, P. and Mosakowski, E. (2004), "Cultural intelligence", Harvard Business Review, Vol. 82 No. 10, pp. 139-46.

[26] Thomas, D. and Inkson, K. (2004), Cultural Intelligence: People Skills for Global Business, Berrett-Koehler, San Francisco, CA.

[27] Levy, O., Beechler, S., Taylor, S. and Boyacigiller, N. (2007), "What we talk about when we talk about 'global mindset': managerial cognition in multinational corporations", Journal of International Business Studies, Vol. 38 No. 2, pp. 231-58.

[28] Javidan, Mansour/ Bowen, David 2013, The "Global Mindset" of managers: What it is, why it matters, and how to develop it, Organizational Dynamics, Vol 42, pp. 145-155.

[29] Clapp-Smith, R./ Vogelsang, G. 2014, Defining the "mindset" in Global Mindset: Modeling the Dualities of Global Leadership, Advances in Global leadership, Vol. 8, 205-228.
[30] Michael J. Morley/ Jean-Luc Cerdin 2010, Intercultural competence in the international business arena, Journal of Managerial Psychology, Vol. 25 No. 8, pp. 805-809.

[31] Mateev, A. V., \& Merz, M. Y. 2014. Intercultural competence assessment: What are its key dimensions across assessment tools? International Association for Cross-Cultural Psychology: Toward Sustainable Development through Nurturing Diversity: 123-134.

[32] Fadel, C. \& Trilling, B. 2012, 21st century learning 21st Century Skills: Learning for Life in Our Times http://www.moskaliuk.com/wasbrauchenunternehmen-um-im-21-jahrhundert-

erfolgreich-zusein-vier-dimensionen/ retrieved: 20.2.2018.

[33] Erin Meyer 2014 Navigating the Cultural Minefield https://hbr.org/web/assessment/2014/ 08/whatsyour-cultural-profile harvard business review, assesed 20.2.2018.

[34] Loewenstein, J., Thompson, L., \& Gentner, D. 2003. Analogical learning in negotiation teams: Comparing cases promotes learning and transfer. Academy of Management Learning \& Education, 2(2): 119-127.

[35] Deardorff, D. K. 2006, Identification and Assessment of Intercultural Competence as a Student Outcome of Internationalization, in: Journal of Studies in International Education, Vol. 10, No. 3, Fall 2006, p. 241-266.

[36] Sitzmann, T./ Ely, K./ Brown, K.G./ Bauer, K.N. 2010, Self-Assessment of Knowledge: A Cognitive Learning or Affective Measure? in: Academy of Management Learning \& Education, Vol. 9, No. 2, p. 169-191.

[37] Oxford Dictionaries 2016; Definition of [...] in English; www.oxforddictionaries.com/de/definition/ englisch/; 24.09.2016.

[38] McLain DL, Kefallonitis E and Armani K (2015) Ambiguity tolerance in organizations: definitional clarification and perspectives on future research. Front. Psychol. 6:344. doi: 10.3389/fpsyg.2015.00344

[39] Spektrum; Lexikon der Psychologie: Ambiguitätstoleranz; http://www.spektrum.de/ lexikon/ psychologie/ambiguitaetstoleranz/743; 24.09.2016. 
[40] Furnham, A., andMarks,J.(2013).Tolerance of ambiguity: a review of the recent literature. Psychology 4, 717. doi:10.4236/psych.2013.49102

[41] Sarkar, M. (2017). 'Psychological Resilience: Definitional Advancement and Research Developments in Elite Sport'. International Journal of Stress Prevention and Wellbeing, 1,3, 1-4. Retrieved from: http://www.stressprevention.net/ volume/volume-12017/volume-1-article-3/

[42] Fletcher, D., \& Sarkar, M. (2013). Psychological resilience: A review and critique of definitions, concepts and theory. European Psychologist, 18, 1223.

[43] Dziatzko, Stehr, Struve, 2018 CSR und Interkulturelle Kompetenz: Auflösung von unternehmensinternen Wertekonflikten anhand von Lösungsansätzen aus dem interkulturellen Kontext, in: CSR und Interkulturelles Management, Springer, Berlin/ Heidelberg. (to be published soon).

[44] Dziatzko, N. Stehr, C. \& Struve, F. 2017 Global Leadership: How to Lead Multicultural Teams Effectively? Journal of Intercultural Management Vol. 9, No. 2, June 2017, pp. 5-29, de Gruyter, DOI 10.1515/joim-2017-0006 